\title{
708 遠心送風機のディフューザ失速に及ぼす通路幅の影響解析
}

\section{Analysis of Diffuser Width Effect on Diffuser Stall in a Centrifugal Blower}

\author{
正 石田 正弘（長崎大） \\ 正 Taufan SURANA（長崎大院） \\ $\bigcirc$ 学 松村 尚幸（長崎大院） \\ 学坂口. 剛史（長崎大院） \\ 正坂口 大作（長崎大）
}

\begin{abstract}
Masahiro ISHIDA, Taufan SURANA, Takayuki MATSUMURA,
Takeshi SAKAGUCHI and Daisaku SAKAGUCHI

Nagasaki University, 1-14 Bunkyo-Machi, Nagasaki 852-8521
\end{abstract}

Key Words : Centrifugal blower, Numerical Analysis, Diffuser stall, Stall suppression

\section{1.まえがき}

遠心羽根車の低流量域で発生する不安定流動注羽根車 入ロインデューサ部の失速に基づくもの、羽根車出ロティ フューザ部の失速に基づくもの、また両者が共存するもの とがあり、不安定流動を回避する設計指針を提案するため にも発生機構を明らかにする必要がある。

Frigne ${ }^{(1)}$ は、開放型遠心羽根車に発生する不安定流動 について、コレクターの有無およびインレットガイドベー ンの有無により、羽根車が失速する条件および羽根なし ディフューザが失速する条件を求め、実験的な整理を行っ ている。またHayami (2)は、小弦節比ティフューザを備え た遷晋速遠心圧箱機において、羽根入口角の変更および羽 根車出口通路幅縮小を行い、運転範囲の拡大および羽根車 効率の改善を達成している。

筆者 ${ }^{(3,4)}$ らも、高比速度型開放型橾心羽根車において、 インデューサ失速およびディフューザ失速が共存する不安 定流動を経験しており、インデューサ失速については、羽 根車入口環状溝により循環流を形成させ、自己修復機能を 持たせることにより不安定流動を回避するとともに、ディ フューザ部の失速については、ディフューザ通路幅維小に より逆流域の抑制を行った。両者を組合わせた試験装置で は、不安定流動の発生する流量を約 $45 \%$ 低流量側へ移行で きている。

本研究では、ディフューザ失速を抑制するために適用 した通路幅縮小効果について、逆流域抑制に及ぼす影響お よび圧力回復に及ぼす影響を 3 次元粘性数值解析により検 証した。

\section{2. 実験および数値解析の方法}

本研究で対象としたインデューサ付高比速度型径向き 羽根遠心羽根車は、入口径 $132[\mathrm{~mm}]$ 、出口径 210.8 $[\mathrm{mm}]$ 、羽根出口高さ $15[\mathrm{~mm}]$ 、羽根出口角 $90\left[^{\circ}\right]$ 、羽根 入口角は先端および根元でそれぞれ $34 、 55\left[{ }^{\circ}\right]$ 、羽根枚数 20枚である。羽根なしディフューザ出口通路幅は、基準 状態では15[mm]、縮小状態では $10[\mathrm{~mm}]$ 、出口半径比は 約 2.0 である。シュラウド隙間は $0.5[\mathrm{~mm}]$ 、羽根車回転 速度は4,000[rpm]とした。数值解析では市販のANSYS-

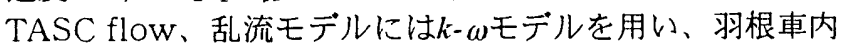
の流れは3次元・定常・非圧縮粘性流孔とした。図1は送 風機子午面断面形状および計算格子を示す。(a)は基準の 平行壁ティフューザ、(b)は八ブ側を絞ったディフューザ (a) Standard parallel wall diffuser
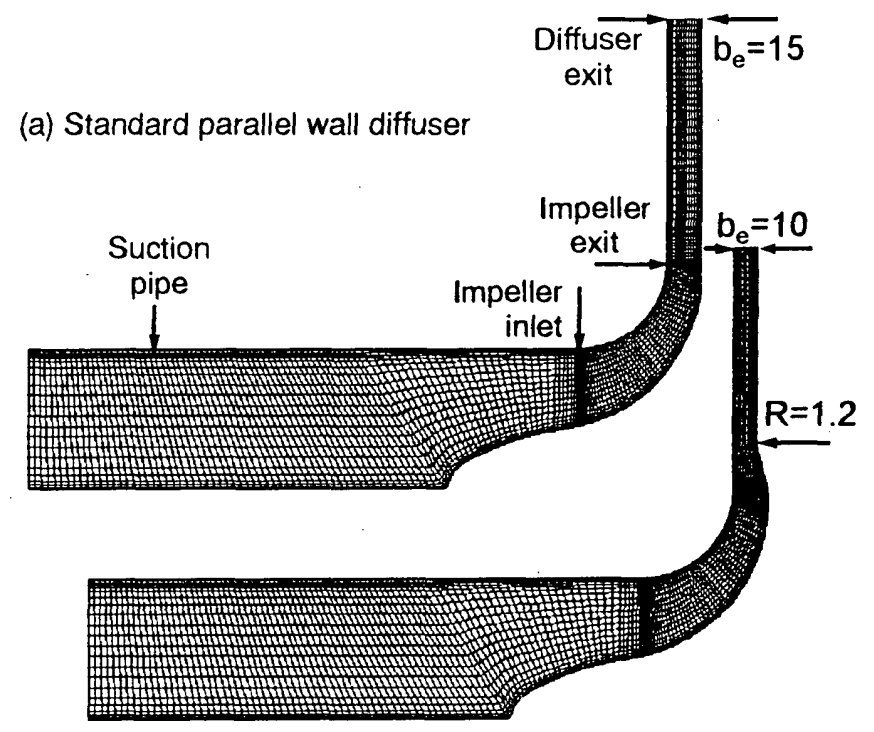

(b) Reduced diffuser width at hub side

Fig. 1 Computational grid for test blower

である。なお、通路幅を縮小する場合、ティフューザ入口 では羽根車出口羽根高さとし、半径比 1.2 までの間で直線 的に縮小させている。計算領域は羽根 1 ピッチ分として周 期境界条件を与え、計算格子は流扎方向199点、ピッチ方 向28点、スパン方向 24 点を選定し、合計 133,728 点とし た。入口境界は羽根車入口から十分遠い2 $50[\mathrm{~mm}]$ 上流 に、出口境界は羽根車出口から $110[\mathrm{~mm}]$ 下流に設定し、 流入流れは一様かつ予旋回なしとした。

\section{3. 実験・解析結果および考察}

図2は実機において計測された送風機特性であり、ディ フューザ出口静圧特性 $\psi_{\mathrm{se}}$ 、羽根車出口静圧特性 $\psi_{\mathrm{s} 2}$ および ディフューザ部静圧上昇量 $\psi_{\mathrm{d}}\left(=\psi_{\mathrm{se}}-\psi_{\mathrm{s} 2}\right)$ を示す。図中の黒 印は压力変動を伴った不安定流動が確認された流量であ り、基準通路幅 $\mathrm{b}_{\mathrm{e}}=15[\mathrm{~mm}]$ の場合には、流量係数 $\phi=$ 0.311 より低流量側で不安定流動が発生し、 $\phi=0.205$ 以下 ではサージに陥った。ディフューザ通路幅を縮小した $\mathrm{b}_{\mathrm{e}}=10[\mathrm{~mm}]$ の場合には、 $\phi=0.306 \sim 0.279$ では同様の不安 定流動が残り、インデューサ失速に基づく不安定流動 ${ }^{(3)}$ と

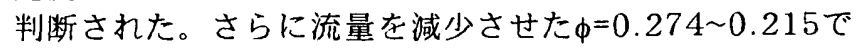

日本機械学会講演論文集 No. 0 4 8-1 ! $04-3-19$, 九州支部第 57 期総会講演会了 


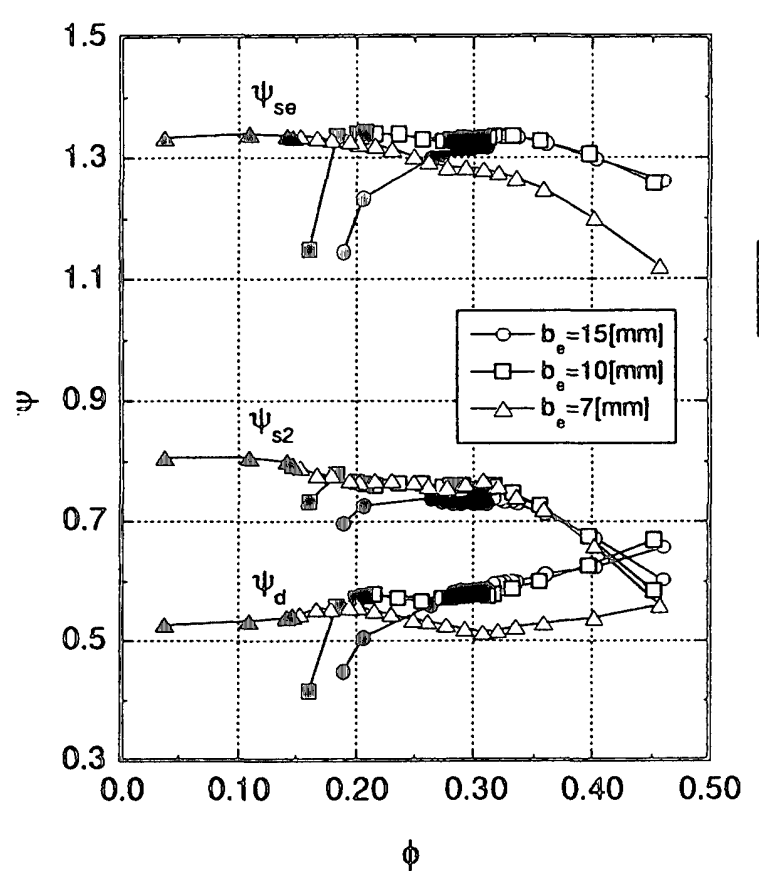

Fig. 2 Experimental characieristics of test blower

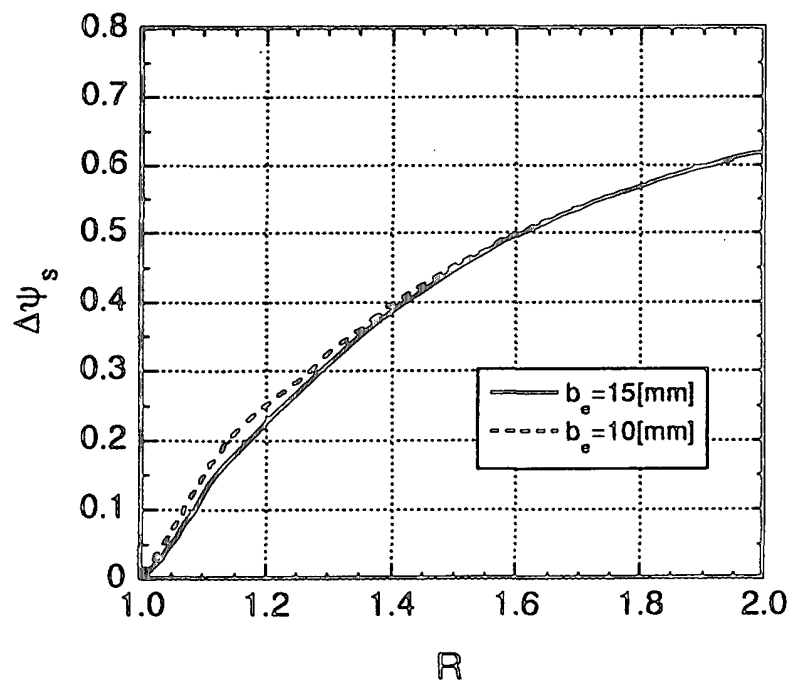

Fig. 4 Effect of diffuser width on pressure rise in vaneless diffuser at design flow rate $\left(\phi_{d}=0.360\right)$

は、不安定流動が消滅し、通路幅縮小がディフューザ失 速の抑制に有効であることを示している。さらに通路幅 を縮小した $\mathrm{b}_{\mathrm{e}}=7[\mathrm{~mm}]$ の場合には、 $\phi=0.151$ まで不安定 流動を抑制できているが、ディフューザ性能を著しく悪 化させている。ディフューザ通路幅を $\mathrm{b}_{\mathrm{e}}=15[\mathrm{~mm}]$ から $10[\mathrm{~mm}]$ 入縮小することによって低流量域特性が改善さ れ、かつ、設計流量近傍でのディフューザ圧力回復率が 影響を受けない理由を調へるため、数值解析により内部 流れを解析した。

図3は羽根車内および羽根なしディフューザ内における 流量減少に伴う逆流域の発生状況を示す。基準ディ フューザの場合、 $\phi=0.250 、 0.205$ のささブ側の逆流 域がディフューザ出口まで到達しており、このことが圧 力脈動を伴った不安定流動を発生する要因である。一 方、通路幅を縮小した場合には、ディフューザ内の逆流 域が消滅している。

図4は設計流量におけるディフューザ内の静圧上昇 $\Delta \psi_{\mathrm{s}}$ を示す。半径比R=1.0 1.3までの区間で、通路幅を緶小 しているにも拘わらず $\mathrm{be}=10[\mathrm{~mm}]$ の方が静圧上昇が大

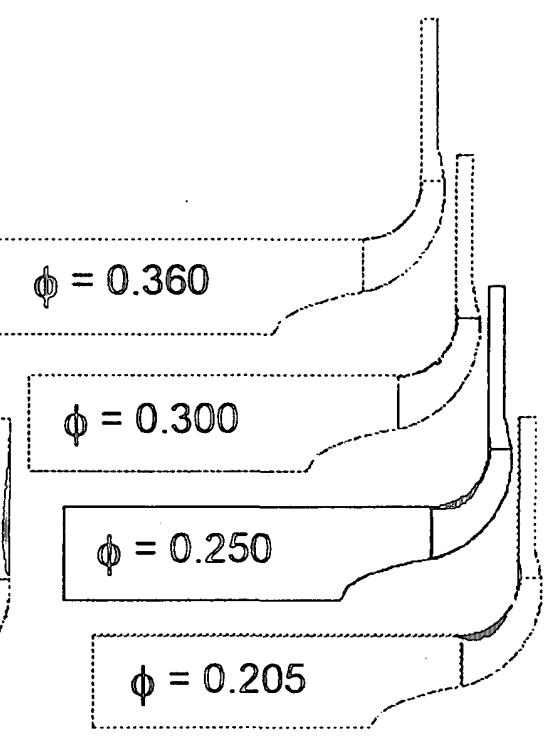

(b) $b_{\mathbf{e}}=10[\mathrm{~mm}]$

Fig. 3 Calculated reverse flow in impeller and in vaneless diffuser

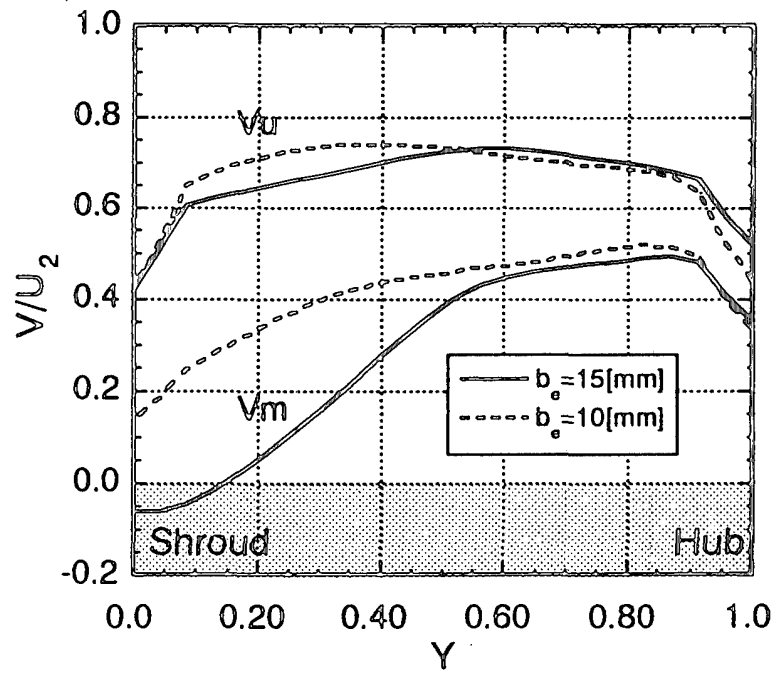

Fig. 5 Velocity distribution between shroud and hub $\left(\phi_{d}=0.360, R=1.2\right)$

きく、また、ディフューザ出口の圧力回復は損なわれてい ない。図5は半径比 $R=1.2$ における周分速度 Vuおよび半径 分速度 $V m$ mのシュラウド・ハブ間分布であり、横軸Yはシュ ラウド壁面からの無次元距離である。be $=15[\mathrm{~mm}]$ の場合 のシュラウド側の逆流がディフューザ入口のVuすなわち運 動エネルギーを減少させていること、およびbe $=15[\mathrm{~mm}]$ の場合の逆流域による有効通路面積の減少とbe $=10[\mathrm{~mm}]$ の場合の有効通路面積がほぼ等価であることが、図4に示す ように、通路幅を縮小したにも拘わらず、設計流量近傍で 平行壁羽根なしディフューザと同じ圧力回復が得られる要 因である。なお、本研究は平成 15 年度科学研究費補助金( 題番号14550154)を受けて実施したものである。

\section{参咢文献}

(1) Frigne,P., van den Braembussche, R., Trans. ASME J. of Gas Turbines and Power, Vol.107, 507-513, (1985)

(2) H.Hayami,ASME Paper 2000-GT-0465 (2000)

(3) T. Surana - ほか 3 名、Proc. 5th JSME-KSME Fluids Engrg. Conf., OS16-4, No.2, 1-6 (2002)

(4) T. Surana •ほか3名、Proc. 7th AICFM, No.30007 (2003) 